\title{
Flow of Mantle Fluids Through the Ductile Lower Crust: Helium Isotope Trends
}

\author{
B. Mack Kennedy' and Matthijs C. van Soest ${ }^{2}$ \\ ${ }^{\prime}$ Center for Isotope Geochemistry \\ Earth Sciences Division \\ Lawrence Berkeley National Laboratory \\ Berkeley, CA 94720 \\ ${ }^{2}$ Noble Gas Geochemistry and Geochronology Laboratory \\ School of Earth and Space Exploration \\ Arizona State University \\ Tempe, AZ 85287-1404
}

\begin{abstract}
Heat and mass are injected into the shallow crust when mantle fluids are able to flow through the ductile lower crust. Minimum ${ }^{3} \mathrm{He} /{ }^{4} \mathrm{He}$ ratios in surface fluids from the northern Basin and Range province, western North America increase systematically from low, crustal values in the east to high, mantle values in the west, a regional trend that correlates with the rates of active crustal deformation. The highest ratios occur where the extension and shear strain rates are greatest. The correspondence of helium isotope ratios and active trans-tensional deformation indicates a deformation enhanced permeability and that mantle fluids can penetrate the ductile lithosphere in regions even where there is no significant magmatism. Superimposed on the regional trend are local, high- ${ }^{3} \mathrm{He} /{ }^{4} \mathrm{He}$ anomalies signifying hidden magmatic activity and/or deep fluid production with locally enhanced permeability, identifying zones with high resource potential, particularly for geothermal energy development.
\end{abstract}


Mantle volatiles, principally water and $\mathrm{CO}_{2}$, play an important role in lithospheric rheology and the production of buoyant fluids that can be injected into the shallow crust. Regional and local trends in the crustal occurrence of mantle volatiles provide insight into the coupling between mantle-crust tectonics $(1,2)$, heat and mass exchange between the mantle and crust (3-5) and the occurrence and distribution of economic resources, such as ore minerals and oil, gas and geothermal fluids ( 6 ). Mantle-derived volatiles in the crust are traceable through helium isotopic compositions of hydrologic fluids (7). Mantle helium once injected into a crustal fluid system will be continuously diluted with radiogenic ${ }^{4} \mathrm{He}$ acquired from the U,Th-rich crust and therefore, surface fluid helium isotopic compositions also provide a measure of the mantle helium flux and the integrated permeability-fluid pressure gradient (flow rate) through the crust (1). To enter the hydrologic system, mantle helium must pass through a ductile lower crust; believed to be an impermeable boundary due to an inability to maintain open fractures on long time scales (9-10). A general assumption is that passage of fluids through this boundary must occur either by direct intrusion and degassing of mantle derived magmas $(6)$ or by diffusion through the ductile boundary layer (11). However, two recent studies in areas void of recent volcanism $(1,12)$ have found evidence for fault controlled advective flow of mantle fluids through the ductile boundary. How and why this occurs is not well understood.

We conducted a regional study of helium isotopic compositions of thermal fluids collected from surface features and wells throughout the northern Basin and Range Province (B\&R), western North America (Figure 1, 13, Table S1). Due to the tectonic influence exerted by the relative motion of the Pacific and North American Plates $(14,15)$, the B\&R is a vast extended region of anomalous thermal gradients, large heat flux, high regional elevation, thin(ned) crust, and lithospheric and asthenospheric mantle melting. Presently, extension is accommodated by high-angle normal faults and the locus of major extension and associated magmatism occurs at the margins of the province $(16)$, primarily within the Walker Lane, a narrow 100-200 km wide trans-tensional volcanic zone along the eastern side of the Sierra Nevada that extends north into a transitional zone between the Sierra Nevada and the subduction related volcanic arc of the Cascades. East of the Walker Lane, B\&R extension occurs at a slowing rate, over a much wider area and in the absence of active or recently active volcanism. 
The highest extension rates in this area occur west of the Central Nevada Seismic Belt (CNSB), a north-northeast trending belt of Holocene seismic activity.

Across the northern B\&R, three general helium isotope trends are apparent. First, ratios $>3.0 \mathrm{Ra}$ occur only at the western margin of the $\mathrm{B} \& \mathrm{R}$, reflecting active or recently active shallow crustal volcanism within the Walker Lane (Coso, Long Valley, Steamboat) and the Cascade volcanic chain (Lassen, Mt. Shasta, Medicine Lake, Crater Lake, Newberry Crater). Second, the preponderance of ratios $>0.6 \mathrm{Ra}$ occur in the northwest $\mathrm{B} \& \mathrm{R}$ in an area ranging from the CNSB west to the transition zone with the Cascade volcanics. Third, east of the CNSB, the helium ratios decline ranging from 0.1 to $0.3 \mathrm{Ra}$.

Collectively, the minimum ${ }^{3} \mathrm{He} /{ }^{4} \mathrm{He}$ ratios define a regional baseline trend of decreasing ratios from west to east as illustrated by the shaded band in Figure 2. East of the Walker Lane and Cascades, the occurrence of mantle helium, as indicated by baseline ${ }^{3} \mathrm{He} /{ }^{4} \mathrm{He}$ ratios $(\sim 0.2-$ $2.0 \mathrm{Ra})$ much greater than average crustal helium $(\sim 0.02 \mathrm{Ra})$, is not supported by magma intrusion as this region has no evidence for current or recent volcanic activity. Instead, the baseline trend is strongly correlated with a change in the direction and magnitude of strain detected by present day GPS velocities (Figure 3; 17, 18). West of the CNSB, a nearly pure eastwest extension rate of $\sim 3 \mathrm{~mm} / \mathrm{yr}$ shifts to $\mathrm{N} 40^{\circ} \mathrm{W}$ and increases to $12-13 \mathrm{~mm} / \mathrm{yr}$. The accelerating dextral shear component is driven by a drag force due to the relative movement of the Pacific and North American Plates (19). We hypothesize that the increase in total strain and, specifically, the northwest orientated dextral shear component significantly enhances average fluid flow rates, allowing for more rapid flow of mantle fluids through the crust, preserving the high ${ }^{3} \mathrm{He} /{ }^{4} \mathrm{He}$ ratios observed at the surface. The enhanced flow rate must persist through the brittle-ductile transition, through the ductile lower crust and into the mantle lithosphere. If, as expected, fluids passing through the ductile crust enter the base of the brittle zone at, or near, lithostatic pressure, then the east-to-west increase in flow rate is primarily governed by an eastto-west increase in average permeability.

The high angle normal faults that presently accommodate B\&R extension and are likely fluid flow pathways are not expected to penetrate the ductile lower crust. In extensional regimes, 
due to gravitational loading, the maximum principle stress is perpendicular to the geoid. With increasing depth, the brittle-to-ductile shift in rheology refracts the maximum stress acting on the fault, resulting in nearly horizontal shear zones or detachment faults at the boundary between the high viscosity upper and low viscosity lower crusts $(20,21)$. Strain localization induced by an increasing dextral shear component superimposed on the extensional stress field must mechanically couple the brittle and ductile crustal zones, generating vertically oriented downward fault splays that extend through the ductile crust and into the mantle. These splays would act as conduits for fluid flow. The close correspondence between helium isotope ratios and the rate of dextral shear strain suggests that fluid flow rate, and, hence, permeability, through the ductile zone is a function of the rate of dextral shear strain. Once flow has initiated, the high pressure pore and fracture fluids may help maintain permeability, enhancing flow through the ductile zone (22).

There are many sampled features that have elevated ${ }^{3} \mathrm{He} /{ }^{4} \mathrm{He}$ ratios with respect to the regional baseline trend. Although a few, such as Roosevelt Hot Spring and Covefort, are associated with crustal magma systems (23), the majority are not. An example of the latter is the Dixie Valley thermal system (Figure 2), where a detailed study (24) found a range in helium isotope ratios $(\sim 0.3-0.8 \mathrm{Ra})$ with the highest ratios restricted to fluids emerging directly from the Stillwater Range Front Fault system, a high angle normal fault that defines the western margin of the valley. A recent east-west high resolution deep magneto-telluric study that crossed through Dixie Valley revealed a zone of low resistance, a possible indication of fluids at a depth of $\sim 25$ $\mathrm{km}$ within the mantle lithosphere (25), suggesting that the Dixie Valley helium anomaly reflects a combination of local, deep production of mantle fluids (zone of low resistance) and a range front fault system with enhanced permeability (high fluid flow rates, hence, high ${ }^{3} \mathrm{He} /{ }^{4} \mathrm{He}$ ratios). The range front fault is the primary conduit supplying $\sim 20 \times 10^{9} \mathrm{~kg}$ of $250{ }^{\circ} \mathrm{C}$ water in support of a 62 MWe geothermal power plant (26). It follows that other "local helium anomalies" may be indicative of similar systems and represent geothermal targets with high potential.

Our regional helium isotope study of fluids across the northern B\&R clearly demonstrates a strong correlation between an east to west increase in the magnitude of dextral shear strain and an east to west increase in baseline helium isotope ratios. In the absence of active or recently 
active magmatism, the elevated helium isotope ratios require amagmatic flow of mantle fluids through the ductile lower crust, suggesting that the increase in dextral shear strain rates creates and maintains permeable pathways through the ductile zone. Elevated helium isotope ratios in surface fluids along amagmatic sections of the San Andreas Fault (1) and a recently observed series of non-volcanic tremor deep $(20-40 \mathrm{~km})$ beneath the same section of the fault provides additional support for the existence of deep mantle fluids, their potential importance in fault mechanisms (26) and non-magmatic fluid flow through the ductile zone.

The high ${ }^{3} \mathrm{He} /{ }^{4} \mathrm{He}$ anomalies superimposed upon the regional trend signify enhanced crustal permeability coupled with local zones of deep fluid production and/or hidden magmatic activity. These local anomalies may be indicative of a heterogeneous distribution of mantle volatiles that promote melt production. Assuming a $\mathrm{CO}_{2} /{ }^{3} \mathrm{He}$ ratio characteristic of mid-ocean ridge basalts of $\sim 2 \times 10^{9}$ molar (6), as a proxy for mantle derived volatiles, the calculated fluid flow rate through the Dixie Valley geothermal system (24) translates into a mantle $\mathrm{CO}_{2}$ flux of $\sim 2-20 \times 10^{-6}$ moles $\mathrm{cm}^{-2} \mathrm{yr}^{-1}$. As of yet, no definitive geochemical or isotopic evidence for the presence of mantle $\mathrm{CO}_{2}$ has been found, other than carbon isotopic compositions $\left(\delta^{13} \mathrm{C}=-6.5 \pm\right.$ 2.5 per mil, 22) not dissimilar from mantle $\mathrm{CO}_{2}(6)$. An estimated $\mathrm{CO}_{2} /{ }^{3} \mathrm{He}$ ratio in Dixie Valley fluids of $\sim 40 \times 10^{9}$ (I3) is 20 times the mid-ocean ridge value, suggesting that a significant fraction $(\sim 95 \%)$ of the $\mathrm{CO}_{2}$ is not mantle derived or, alternatively, the sub-continental mantle $\mathrm{CO}_{2} /{ }^{3} \mathrm{He}$ ratio is significantly greater than observed at mid-ocean ridges.

The Earth's crust stores an enormous resource of thermal energy produced primarily from the radioactive decay of $\mathrm{U}, \mathrm{Th}$, and $\mathrm{K}$ dispersed throughout the Earth. It has been estimated that within the United States (excluding Hawaii and Alaska) there is $\sim 9 \times 10^{16} \mathrm{kWh}$ of accessible geothermal energy. This is a sizable resource compared to the total energy consumption in the United States of $3 \times 10^{13} \mathrm{kWh}$ annually. In order for geothermal systems to develop and mine the heat source naturally, adequate fluid sources and deep permeable pathways are a necessity. The deep pathways provide access to high temperatures that can drive fluid convection cells. Helium isotopes provide a quantitative or, at least, a qualitative estimate of deep permeability from surface measurements, and anomalies super-imposed on regional trends can identify potential resources. 


\section{References}

1. B. M. Kennedy et al., Science 278, 1278-1281 (1997).

2. D. L. Newell, L. J. Crossey, K. E. Karlstrom, T. B. Fischer, D. R. Hilton, D.R., GSA Today 15 (12), 4-10 (2005).

3. F.J. Spera, Contr. Min. Pet. 88, 217-232 (1984).

4. G. Holland, C. J. Ballentine, Nature 441, 186-191 (2006).

5. C. J. Ballentine, B. Marty, B. S. Lollar, M. Cassidy, Nature 433, 33-38 (2005).

6. C. J. Ballentine, R. Burgess, B. Marty, Rev. Mineral. Geochem. 47, 539-614 (2002).

7. Without mantle influence, crustal fluids are dominated by ${ }^{4} \mathrm{He}$ produced from the natural radioactivity of $\mathrm{U}$ and $\mathrm{Th}$ and characterized by very low ${ }^{3} \mathrm{He} /{ }^{4} \mathrm{He}$ ratios of $\sim 0.02 \mathrm{Ra}$ (where $\mathrm{Ra}=1.4 \times 10^{-6}$, the ratio in air). Mantle fluids without significant crustal influence are strongly enriched in ${ }^{3} \mathrm{He}$, with typical ratios ranging from $\sim 6-35 \mathrm{Ra}$, depending on the mantle source (e.g. plume volcanism vs. MORB vs. back arc volcanism).

8. J. D. Byerlee, Geophys. Res. Lett. 17, 2109-2112 (1990).

9. J. D. Byerlee, Geology 21, 303-306 (1993).

10. N. H. Sleep, M. L. Blanpied, Nature 359, 687-692 (1992).

11. T. Torgersen, J. Geophys. Res. 98 (B9), 16,257-16,269 (1993).

12. J. T. Kulongoski, D. R. Hilton, J. A. Izbicki, Geochim. Cosmochim. Acta 69, 3857-3872 (2005).

13. Materials and Methods are available as Supporting Material on Science Online.

14. C. H. Jones et al., Tectonphysics 213, 57-96 (1992).

15. M. L. Zoback, G. A. Thompson, Geology 6, 111-116 (1978).

16. T. Parsons, in Developments in Geotectonics 25, Publication \#264 of the International Lithosphere Program, K.H. Olsen, Ed. (Elsevier, New York, NY, 1995), pp. 277-324.

17. R. A. Bennett, B. P. Wernicke, N. A. Niemi, A. M. Friedrich, A.M., Tectonics 22, doi:10.1029/2001TC001233 (2003).

18. W. C. Hammond, W. Thatcher, J. Geophys. Res. 109 (B08403), doi:10.1029/2003JB002746 (2004). 
19. L. M. Flesch, W. E. Holt, A. J. Haines, B. Shen-Tu, B., Science 287, 834-836 (2000).

20. G. A. Bradshaw, M. D. Zoback, Geology 16, 271-274 (1988).

21. H. J. Melosh, Nature 343, 331-335 (1990).

22. S. F. Cox, Earth Planets Space 54, 1121-1125 (2002).

23. D. L. Nielson, J. N. Moore, Geothermal Resources Council, Trans. 3, 503-506 (1979).

24. B. M. Kennedy, M. C. van Soest, M.C., Geothermics 35, 26-43 (2006).

25. P. E. Wannamaker, W. M. Doerner, D. P. Hasterok, Annual Meeting Geolog. Soc. Am. GSA2005-225 (2005).

26. D. D. Blackwell, B. Gollan, D. Benoit, Geothermal Resources Council, Trans. 24, 223-228 (2000).

27. R. M. Nadeau, D. Dolenc, Science 307, 389 (2005).

29. This work was supported by the U. S. Department of Energy, Office of Basic Energy Sciences and Office of Geothermal Technologies under contract DE-AC02-05CH11231.

Supporting Online Material

www.science.org

Materials and Methods

Table S1 


\section{Figure Captions}

Figure 1: Sample location map of the B\&R and surrounding areas. Symbol colors delineate ${ }^{3} \mathrm{He} /{ }^{4} \mathrm{He}$ ratios, expressed as $\mathrm{Rc} / \mathrm{Ra}$ (the air-corrected sample ratio normalized to the ratio in air). Symbol shapes identify the type of thermal area. Tectonic zones are outlined: red, northern B\&R; yellow, the Walker Lane trans-tensional zone (WL) and the central Nevada seismic belt (CNSB), green, the Sierra Nevada batholith (SN); and light blue, the Cascades volcanic zone. Label TZ refers to the transition zone between the Cascades, WL and the B\&R.

Figure 2: The air-corrected helium isotopic composition of geothermal fluids above $38^{\circ} \mathrm{N}$ latitude in the $\mathrm{B} \& \mathrm{R}, \mathrm{TZ}$ and Cascades plotted as a function of longitude. The shaded curve depicts an east-to-west baseline trend defined by minima in the local ${ }^{3} \mathrm{He} /{ }^{4} \mathrm{He}$ ratios.

Figure 3: A compilation of present day GPS strain rates across the northern $B \& R$ relative to the North America reference frame. The data are from GPS networks located in a band from $38^{\circ}$ to $41^{\circ} \mathrm{N}$ latitude $(15,16)$. West of $242-242.5^{\circ} \mathrm{E}$ longitude, the data show a combined increase in total magnitude of strain and an increase in lateral dextral shear strain superimposed on E-W extension. This is most evident in the Walker Lane, but impacts most of the B\&R in and to the northwest of the CNSB, as illustrated by the Figure 3 insert taken from (19). The broad colored band is the regional baseline helium isotope trend from Figure 2, shown super-imposed on the trends in strain rate. 


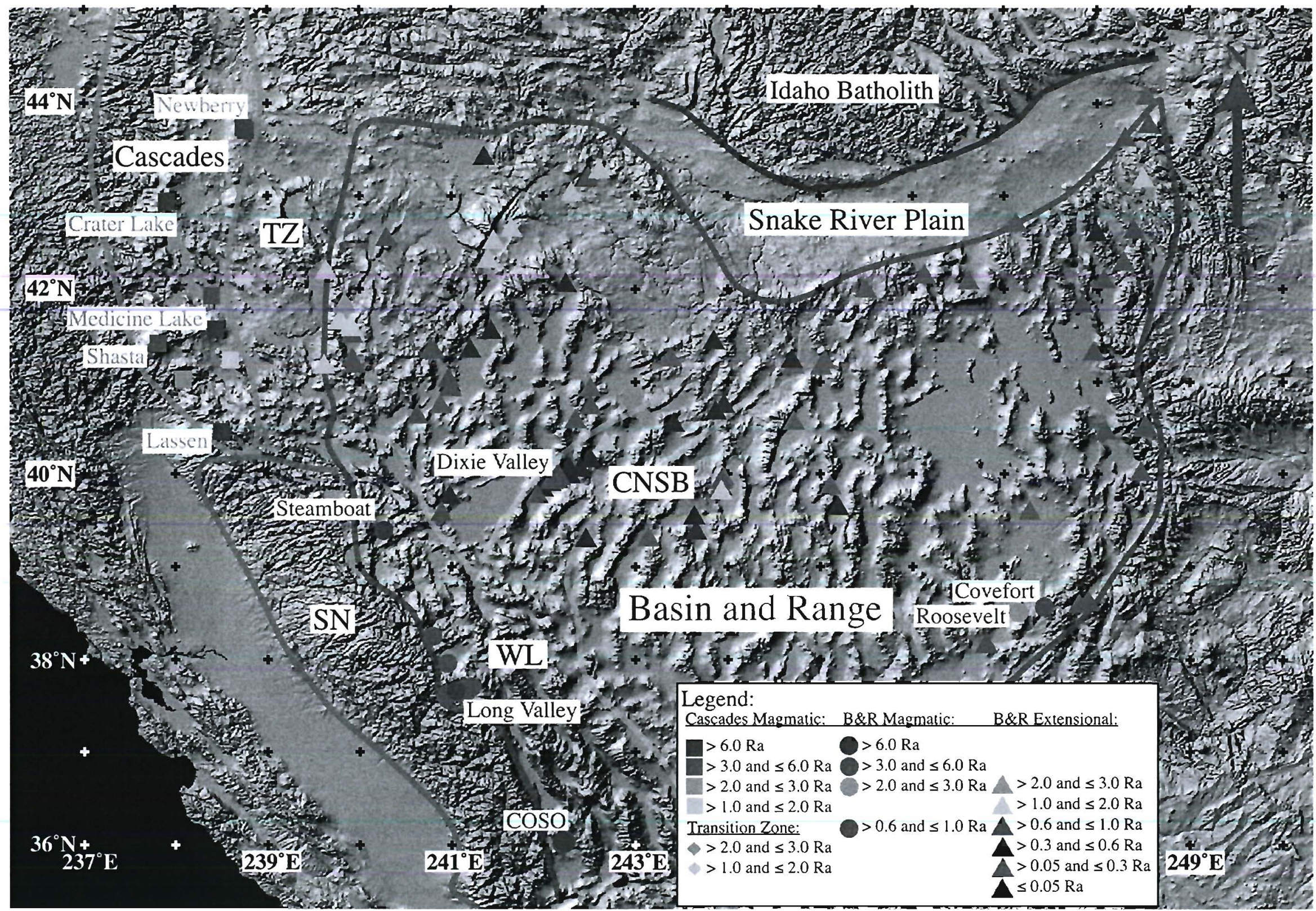




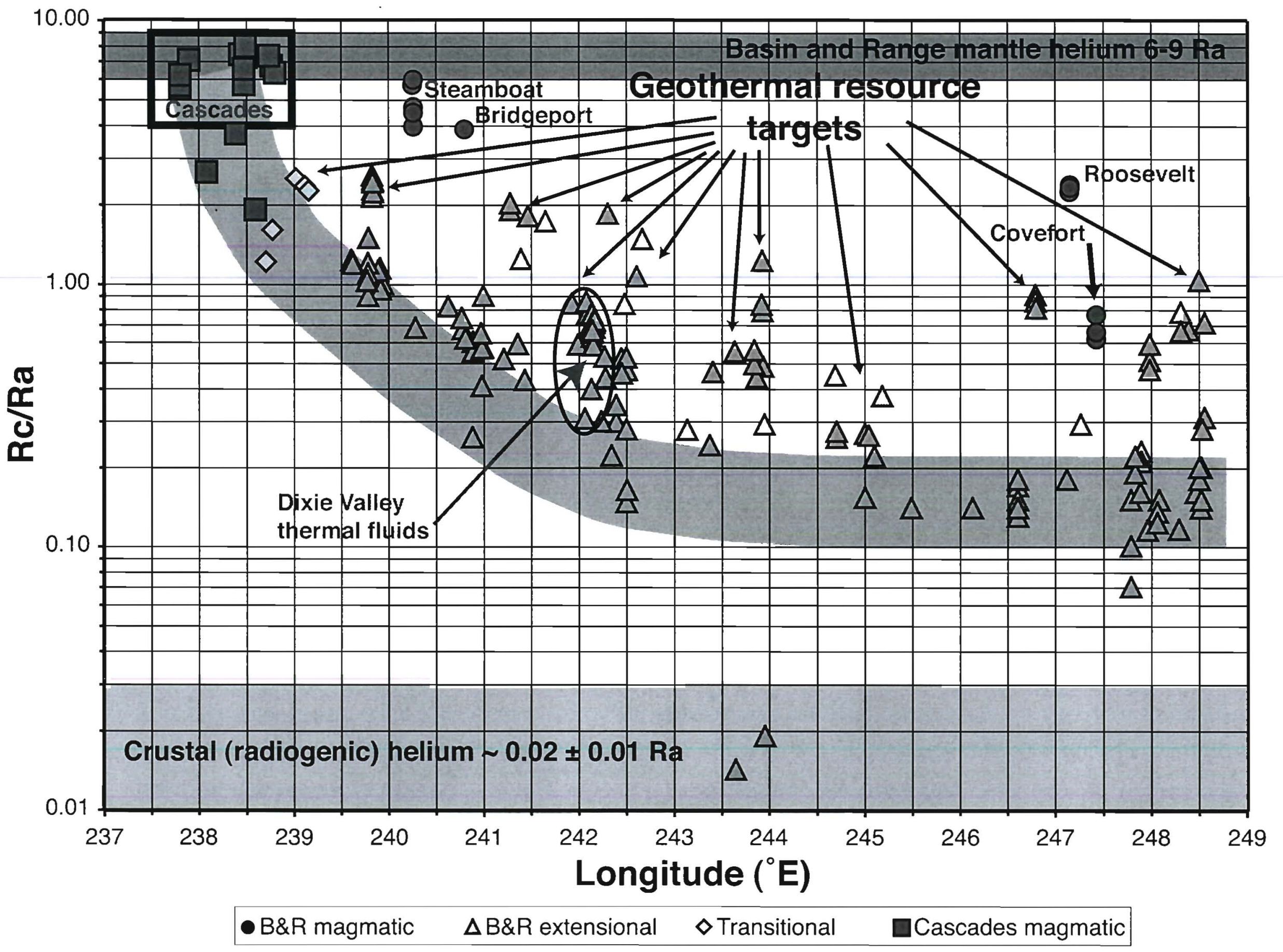




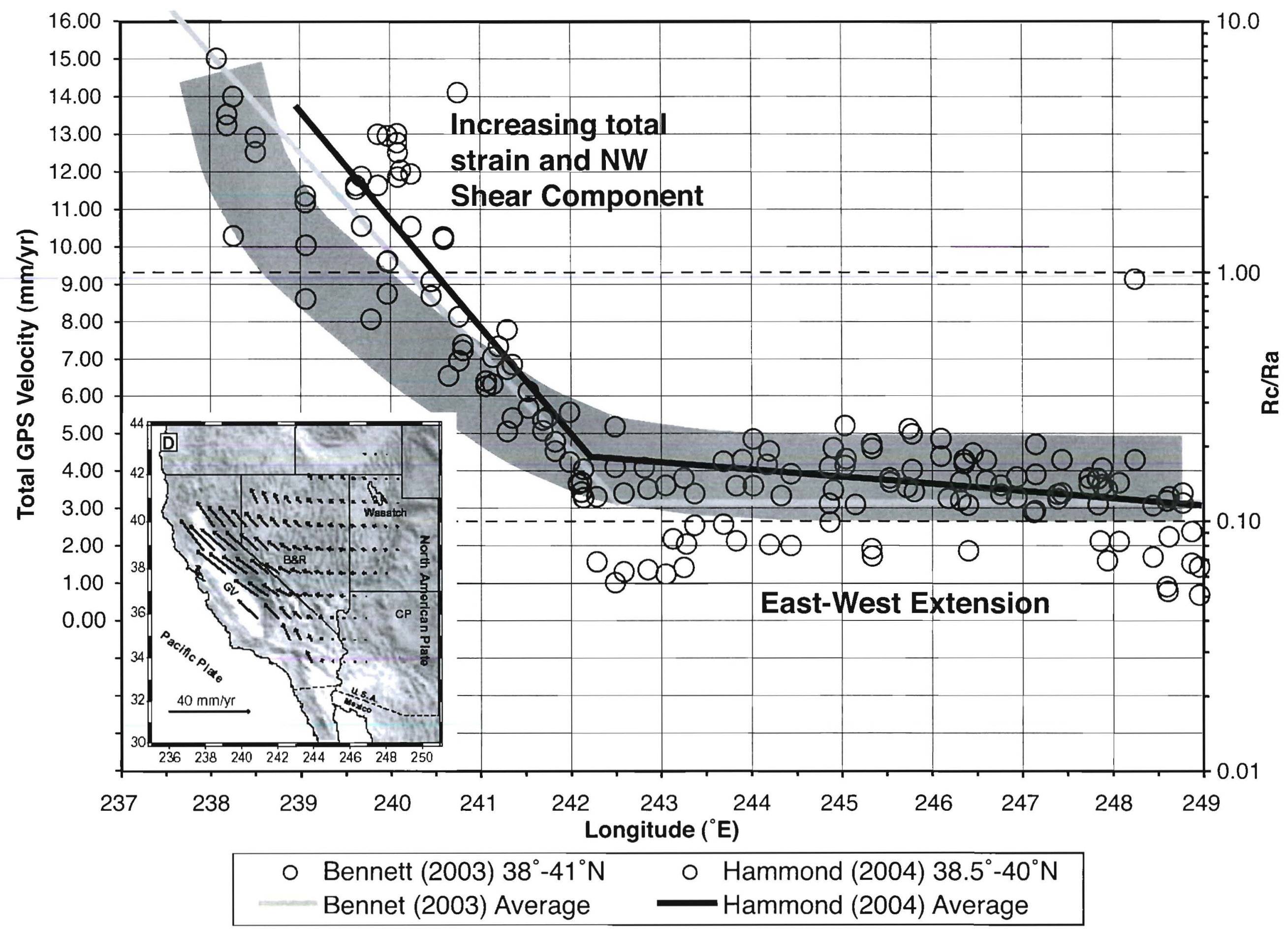

